\title{
Acoustic Parameters of Classrooms in Akwa Ibom State, South-South Nigeria
}

\author{
Aniefiok O. Akpan Solomon M. Adiamkpo Edidiong S. Abaka \\ Physics Department, Akwa Ibom State University. PMB 1167, Ikot Akpaden, Mkpat Enin LGA, Akwa Ibom \\ State, Nigeria
}

\begin{abstract}
It has been proven that acoustic conditions in classrooms have great influence on the performance of students and give stress to the teachers. Long reverberation time may also deteriorate speech quality by reducing the signal to noise ratio (SNR). This work aimed at predicting the absorption "a" and thereby calculating the reverberation time of some classrooms in Akwa Ibom State, South-South Nigeria using simple Sabin equations and to make appropriate recommendations where they fall short of the recommended standard of 0.75 to 1.00 seconds for classrooms and lecture halls. Effective absorption coefficients of materials used for the construction of the classrooms under study were used for the calculation of the absorption of these classrooms while the Sabin equation was used to calculate the reverberation time. The results show that all the classrooms under study which were representatives of the classrooms in the area of study had reverberation time that were within the recommendation time of 0.75 to 1.00 seconds. The classrooms in the area of study could be certified to be good for lecture delivery by the teachers, good speech intelligibility and lecture assimilation of the students.
\end{abstract}

Keywords: Absorption coefficient, Absorption, Reverberation time, Speech intelligibility

DOI: $10.7176 /$ JEES/11-9-05

Publication date:September $30^{\text {th }} 2021$

\section{Introduction}

Acoustics comfort is neglected in lecture halls and classrooms in some of our primary, secondary schools and universities and this has gone a long way to influence students' performance both in classroom discussions and examinations (Bradley, J. S ; Sato, H. 2008). Effective communication during lectures and knowledge from instructors, teachers and lecturers are also greatly affected.

Sound in classrooms that gets into the ear of students are both direct and reflected sound, it has to be clear enough when listening to It (Tang S. K. et al, (2006). The amount of reflected sound should reinforce the direct sound to make it loud enough and at the same time there should be no echoes or noticeable overlapping in syllables. The reverberation time of a room is the acoustic property that plays an important role in the enrichment of sound for the listening audience (Schroeder M. ; Gerlach, R.,(1994) ; Zannin ; Zwirtes (2009). It should be long enough to enhance the blending of sounds but short enough to avoid excessive overlapping and confusion. Reverberation time in room acoustics has been found to be the most common parameter and it can be described as the persistence of sound after a source has stopped and it is the time needed to a reduction of $60 \mathrm{~dB}$ in the sound pressure level (Schultz, T. (1971), (Tang S. K. et al, (2006). Reverberation time has the advantage of being steady throughout the space and predictable using single formula (Sabine, W. (1992).

\section{Statement of the problem}

Acoustic conditions of classrooms have been proven to have significant influence on the performance of students and working stress of teachers or lecturers (Schultz, T. (1971); Shield, B.et al (2015). One may experience difficulties on learning and social interaction as well as having greater time lost to disruptive activities during lessons due to poor acoustics. It has been reported that reverberation times longer than 0.5 seconds deteriorate speech quality in classrooms (Shield, B.et al (2015) ; Smirnova,J. and Ossowski, A. (2005); Zannin and Zwirtes (2009). Thus effect is as a result of late reflections on direct and early sounds. This work is aimed at predicting the reverberation time of classrooms using single formulas and to make appropriate recommendations where they fall short of the recommended standard of 0.75 to 1.00 for classroom and lecture halls. Long reverberation times may also deteriorate speech quality by reducing the signal-to-noise ratio (SNR). This effect depends on the distances of speech and noise source to the listeners. Noise levels are increased in a room resulting in smaller SNR when tumultuous pupils are close to the listener thereby exciting the classroom when the teacher is more far away. The opposite occurs when the listener finds the noise source far away than the speech source.

Noise sources in classrooms include equipment noise ( HVAC systems), external sources and the students themselves( Nijs, L. and Rychtarikova. M. (2021); Smirnova,J. and Ossowski, A. (2005). Once an adequate SNR has been achieved, room acoustics should be optimised by increasing early-to-late sound energy in ratios. This could be achieved by using a combination of diffusers and sound absorbing materials. Too short reverberation times due to excessive use of sound absorbing materials are undesirable and should be avoided as they force the teachers or lecturers to speak louder in an attempt to be heard by students at the back row. This increases the risk 
of developing voice disorder.

\section{Literature review}

Tang et al.(2006) measured the reverberation times and noise levels in the classroom of primary and middle schools of Hong Kong and derived the relationship between the reverberation times and speech transmission indices for speech transmission design. Zannin et al (2009) measured the reverberation times and indoor-outdoor sound insulation efficiency in the public school facilities of Brazil and studied the actual conditions of the acoustic environment quality. Sale and viljanen (1995) investigated the optimal acoustic treatment for speech rooms rather than the optimal placement of sound absorbers for maximum efficiency as they viewed the amount of materials used between the absorption material arrangements tested. They concluded that the optimal arrangement of sound absorption materials to achieved acceptable acoustic conditions for speech involved the distributions of material in at least two surfaces (ceiling and back wall) and covering around $30 \%$ of the total surface area of walls and ceiling. They reported that using larger amount of absorbing material results in an increment in the cost of building materials that leads to an insignificant improvement in speech intelligibility and excessive attenuation of sound levels. Bistafa and Bradley (2000) studied both different acoustic treatments with varying amount of sound absorbing material and the efficiency of sound absorbing materials by testing the same amount in different configurations. They also compared the accuracy of seven analytical expressions . Sabine et al (1992) used two pieces of room acoustic software (Odeon 2.6 and Raynoise 3.0) to predict reverberation times measured in a simulated rectangular classroom, for different configurations of sound absorbing materials. Their study concluded that none of the analytical expressions or the acoustic software was able to consistently predict reverberations times within a predictable accuracy of $10 \%$. The most accurate analytical expression was shown to depend on the amount and distribution of sound absorbing material in the room. According to them, the expression developed by Arau-Puchades (1988) was concluded to be the formulas that predicted reverberations times with the smallest average relative error. Their reverberations time measurements for the different configurations of sound absorbers showed differences in average reverberation time up to 0.35 which was attributed to the higher efficiency of sound absorbing materials when materials are uniformly distributed in the room. Ruggiero et al. (2016) determined the distribution of the sound pressure level in school music rooms from a simulation that used general purpose software and studied the installation position of the sound absorption panel and verified the effect on the reverberation time. Nocera et al (2004) investigated the acoustic environment quality of a lecture venue where a tensile membrane structure was used and proposed an improvement method by simulation. Schroeder and Gerlach (1994) computed reverberation times in rooms of different shape with varying absorber location. In their computations the a authors rejected the traditional formulas of Sabine and Eyring(1994) as these formulas do not consider room shape and absorber locations, factors that have been shown to have an influence in reverberation times. The first-order Markov theory which they used to calculate the probabilities of a sound ray to hit a given wall taking into account the wall that was previously hit provided reverberation times closer to experimental measurements than those given by traditional formulas. Their results consistently showed that the smallest reverberation times were obtained when absorbers were located on the smallest walls. It was also reported that for rooms with nearly equal dimensions, absorber locations had no significant influence in computed reverberation times. Shih et al (2016) obtained room acoustic characteristics of various design, conditions by simulation using general purpose software for a container house with a low acoustic environment quality. Diaz et al (2005) measured the reverberation times of 11,687 rooms targeting closed-space bedrooms and hiring rooms. Watanabe et al. and Hanyn et al (2006) conducted auditing experiments on hiring room spaces and studied the impact of change in the average sound absorption coefficient on thing such as sense of luxury and preferences. The benefits of good architectural acoustics design to occupant include increase in productivity, improved health, good perception of surrounding activities in terms of their satisfaction and preference, good logical thinking, better attention and alertness to surrounding activities and high motivation to work. Negative phonological effects will also be reduced.

\section{Theoretical Framework}

The sound absorption coefficient of a reflecting/absorbing surface is defined as the fraction of the energy absorbed during each reflection at a specific frequency. The process of sound absorption is a conversion of acoustic energy to thermal energy which takes place at the material surface.

If the sound absorption coefficient is known for each surface in a room, the sound absorption "a" in sabins can be calculated as;

$a=\alpha_{1} S_{1}+\alpha_{2} S_{2}+\alpha_{3} S_{3}$

In summation form

$a=\sum_{i} \alpha_{i} S_{1}---------------------$ 
Where $\alpha_{i}=$ Sabine sound absorptioncoefficientofsurfaceareai

$$
S_{i}=\text { area of the surface }
$$

The reverberation time of the room is then calculated as;

$$
T=0.161 \frac{V}{a}----------------------
$$

Where $T=$ reverberation time to reduce the sound intensity from a level of $60 \mathrm{~dB}$ above the threshold of auditability to the threshold of audibility.

$\mathrm{V}=$ room volume

$\mathrm{a}=$ sound absorption

The Sabin is the unit of sound absorption, "a", where 1 sabin is the amount of sound absorbed by a theoretically perfect absorptive surface of area equal to $1 \mathrm{~m}^{2}$. This sound intensity in a room decreases as the sound absorption of the room increase.

\section{Methodology}

Eight (8) schools were sampled for this study, six (6) in Ikot Abasi Local Government Area and two (2) in Mkpat Enin Local Government Area of Akwa Ibom State, South- South Nigeria. The schools are all public schools and are rectangular in shape .

The effective absorption coefficients of the materials used for the construction of the school blocks for this study are as shown in table 2.0. The absorption "a" and reverberation time were calculated using equation (1) and (2) respectively.

\section{About the study areas}

Ikot Abasi, also called Opobo, formerly Egwanga, Port town, Akwa Ibom state, southern Nigeria. The town lies near the mouth of the Imo (Opobo) River. Situated at a break in the mangrove swamps and rain forest of the eastern Niger River delta, it served in the 19th century as a collecting point for slaves. Ikot Abasi is located in the south west corner of Akwa Ibom State, Nigeria. It is bounded by Oruk Anam Local Government Area in the north, Mkpat Enin and Eastern Obolo Local Government Areas in the east and the Atlantic Ocean in the south. The Imo River forms the natural boundary in the west separating it from Rivers State. The people of Ikot Abasi are made up of the Ibibio ethnic group with diverse cultural heritage and tradition. They speak the Ibibio language. Ikot Abasi is made up of five clans namely: Ikpa Edemaya Clan, Ikpa Ibekwe Clan, Ikpa Nnung Assang Clan, Ukpum Ette Clan and Ukpum Okon Clan.

Mkpat Enin LGA has an area of 322.352 square kilometres (124.461 sq mi) and it's the second largest local government area in Akwa Ibom state. The LGA is located within the industrial belt extending from Eastern Obolo, Etinan, Oruk Anam, Onna, to Ikot Abasi. The people are traditionally Ibibio speakers. Mkpat-Enin is located in the south south region of Nigeria and is a town and a Local Government Area (LGA) of Akwa Ibom State. It sits at an altitude of approximately 185 metres (607 ft) above sea level.'The population was 178,036 based on the 2006 census. The area is rich in oil and natural gas; oil was discovered in Ikot Akpa/Ekop as early as 1953. Forest reserves in the local government area include timber and palm produce. $\square$

\section{Results and Discussion}

As shown in table 4.0, the classroom in Methodist Secondary School (SCH 3), Ete in Ikot Abasi Local Government Area and that of Essetang High School (SCH8) in Mkpat Enin had the highest reverberation time of 0.96 followed by SS Peter and Paul Primary School (SCH6) with a reverberation time of 0.93. Secondary Commercial School (SCH1), Ibekwe, Community Secondary Commercial School (SCH4), Odoro Atan, Ukpum Okon Comprehensive Secondary School (SCH5) and Methodist Central School (SCH2), Ukpum Okon, all in Ikot Abasi Local Gorvernment Area had reverberation time of $0.91,0.90,0.86$ and 0.81 respectively. The least reverberation time of 0.80 was from St Paul Group School (SCH7), Ekim in Mkpat Enin Loca Government Area. As shown in table 1.0 , the recommended reverberation time for classrooms and speech rooms is 0.75 to 1.00 . This result of the calculated reverberation time of classrooms for all the schools investigated fall within this range.

\section{Conclusion}

It can therefore be concluded that all the classrooms under this study have met the recommended standard of reverberation time and as such could be certified good for lecture delivery, enhanced speech intelligibility and better lecture assimilation by students.

\section{AKNOWLEDGEMENT}

We sincerely thank all the school heads and teachers that gave us the permission to take measurements in their 
school. The pupils are not forgotten especially when we remember some of the question like " sir, what are you going to do with these measurement" they asked us.

\section{REFERENCES.}

1. Arau - Puchase H. (1988): An improved reverberation formula; Acta Acust. United Acust, 65, 163-180.

2. Beradi, U. (2014): Simulation of Acoustic parameters in rectangular Churches. Journal of Building Performance Simulation, 7, 1-16

3. Bistafa, S. R. and Bradley, J. S. (2000): Predicting reverberation time in a simulated classroom. Journal of Acoustical Society of America. $1721-1731$.

4. Bradley, J. S and Sato, H. (2008): The intelligibility of speech in elementary school classrooms. Journal of Acoustical Society of America.123, 2078 -2086.

5. Chaing, C. M. and Lai, C. M.(2008): Acoustical environment evaluation of joint classrooms for elementary schools in Taiwan. Building Environment. 43,1619 -1632.

6. Daiz,C. and Pedrero, A.(2005): Reverberation time of furnished rooms in dwelings. Applied Acoustics. 66, $945-956$.

7. Eyring, C. F. (1930): Reverberation time in "dead" rooms. Journal of Acoustical Society of America. 1, 217 $-241$.

8. Hodgson, M. and Nosal, E. M. (2002): Effect of noise and occupancy on optimal reverberation times for speech intelligibility in classrooms. Journal of Acoustical Society of America, 111, 931 - 939.

9. Lubman, D. and Sunderland, L. C. (2017): Classroom acoustics for the $21^{\text {st }}$ century. In procedings of the $19^{\text {th }}$ international congress on acoustics, Madrid, Spain. 2 - 7

10. "Mkpat Enin". Akwa Ibom State Government. Archived from the original on 2011-10-06. Retrieved 200912-08.

11. Nijs, L. and Rychtarikova. M. (2021): Calculating the ultimate reverberation time and absorption coefficient for good speech intelligibility in classrooms design using U50. Acta Acust. United Acust. 97,93 - 102

12. Nocera F. et al (2004): Acoustic quality of a tensile membrane structure used in a lecture hall and proposal for its improvement. Building Acoustics. 21, 287 - 304.

13. Ruggiero, A. and Russo, D.(2016); Acoustic design and experimental verification of school music rooms, a case study. Applied Acoustics , 107, 1 -9.

14. Sabine, W. (1992): Reverberation. The American architect and the engineering record; Sabine WC prefaced Beranek LL. Collected papers in Acoustics, Peninsula publishing; Los Altos,CA, USA.

15. Sala, E. and Viljanin, V. (1995): Improvement of acoustic conditions for speech communication in classrooms. Applied Acoustics. 45, 81 -91.

16. Schroeder M. and Gerlach, R. (1994): Diffusion, room shape and absorber location influence on reverberation time. Journal of Acoustical Society of America. 56, 1300 - 1301.

17. Schultz, T. (1971): Diffusion in reverberation rooms. Journal of Sound and Vibration. 16, $17-28$.

18. Shih et al (2016): Improvement on acoustic characteristics of a small space using material selection. Engineering Computation. 33, 1800 -1809

19. Shield, B. M. and Dockrell, J. E.(2003): The effect of noise at children in school, a review. Building Acoustics. 10, $97-116$

20. Shield, B.et al (2015): A survey of acoustic conditions and noise levels secondary school classrooms in England. Journal of Acoustical Society of America. 137, 177 - 188.

21. Smirnova,J. and Ossowski, A. (2005): A method for optimising absorptive configurations in classrooms. Acta Acust. United Acust, 91, 103 -109.

22. Tang S. K. and Yeung, M. H. (2006): Reverberation time and speech transmission indices in classrooms. Journal of Sound and Vibration. 294, 596-607.

23. Watanabe, D et al (2011): Fundermental study of sound absorption for comfortable sound environment in residences. Journal of Environmental Engineering. 76, 345 - 353.

24. Zannin, P. H. T. and Zwirtes, D. P. Z. (2009): Evaluation of the acoustic performance of classrooms in public schools. Applied Acoustics 70, 626 - 635 
Table 1.0: Recommended reverberation times for music and speech rooms

Source: Sound control construction principles and performance. Second edition.

\section{Music}

Rehearsal rooms

Chamber music

Orchestral/choral average church music

Large organ liturgical choir

Speech

Small offices

Classrooms, lecture room

Work rooms

\begin{tabular}{llc}
\multicolumn{3}{c}{ Reverberation Times (Sec) } \\
0.80 & To & 1.00 \\
1.00 & To & 1.50 \\
1.50 & To & 2.00 \\
2.00 & To & 2.25 \\
& & \\
0.50 & To & 1.00 \\
0.75 & To & 1.00 \\
1.00 & To & 2.00
\end{tabular}

Table 2.0: Effective absorption coefficients at different frequencies.

Source: L.E. Kinsler and A. R. Frey. Fundamentals of Acoustics, Second edition, John Wiley and Sons Inc.

\section{Material}

Acoustic panelling

Acoustic plaster

Brick wall, unpainted

Draperies, light

Draperies, heavy

Felt

Floor, concrete

Floor, wood

Floor, carpeted

Glass

Marble or glazed tile

Plaster

Rock wool

Wood panelling, pine
Frequency $\left(\mathrm{H}_{\mathrm{z}}\right)$

$\begin{array}{lll}12.5 & 500 & 2000 \\ 0.16 & 0.50 & 0.80 \\ 0.30 & 0.50 & 0.55 \\ 0.02 & 0.03 & 0.05 \\ 0.04 & 0.11 & 0.30 \\ 0 & 0.50 & 0.82 \\ 0.13 & 0.56 & 0.65 \\ 0.01 & 0.02 & 0.02 \\ 0.11 & 0.37 & 0.27 \\ 0.04 & 0.05 & 0.05 \\ 0.01 & 0.01 & 0.02 \\ 0.04 & 0.04 & 0.05 \\ 0.35 & 0.63 & 0.83 \\ 0.10 & 0.10 & 0.08\end{array}$

Table 3.0: Showing schools, codes, and construction material of the schools.

\begin{tabular}{|l|l|l|l|l|}
\hline Schools & \multirow{2}{*}{ Codes } & \multicolumn{3}{|c|}{ Construction materials } \\
\cline { 3 - 5 } & & Well & Ceiling & Floor \\
\hline Secondary commercial schools, Ibekwe, Ikot Abasi & SCH 1 & Plaster & Asbestos (felt) & Concrete \\
\hline Methodist Central School, Ibekwe, Ikot Abasi & SCH 2 & Brick & Asbestos (felt) & Concrete \\
\hline Methodist Secondary School, Ete, Ikot Abasi & SCH 3 & Brick & Asbestos & Concrete \\
\hline $\begin{array}{l}\text { Community Secondary Commercial School, Odoro Atan, } \\
\text { Ikot Abasi }\end{array}$ & SCH 4 & Plaster & Asbestos & Concrete \\
\hline $\begin{array}{l}\text { Ukpum Okon Comprehensive Secondary School, Okon, } \\
\text { Ikot Abasi }\end{array}$ & SCH 5 & Plaster & Asbestos & Concrete \\
\hline SS Peter \& Paul Primary School, Essene, Ikot Abasi & SCH 6 & Brick & Asbestos & Concrete \\
\hline St. Paul group School, Ekim, Mkpat Enin & SCH 7 & Plaster & Asbestos & Concrete \\
\hline Essetan High School, Ekim, Mkpat Enin & SCH 8 & Plaster & Asbestos & Concrete \\
\hline
\end{tabular}

$$
\mathrm{SCH}=\mathrm{SCHOOL}
$$

Table 4.0: Showing average absorption "a", reverberation time " $\mathrm{t}$ " and dimensions of the classroom.

\begin{tabular}{|c|c|c|c|c|c|c|}
\hline Schools & Length (m) & Width (m) & Height (m) & $\begin{array}{c}\text { Volume } \\
\left.\mathbf{( m}^{\mathbf{3}}\right)\end{array}$ & $\begin{array}{c}\text { Average } \\
\text { Absorption } \\
\text { (sabins) }\end{array}$ & $\begin{array}{c}\text { Reverberation } \\
\text { Time (sec) }\end{array}$ \\
\hline SCH 1 & 7.63 & 7.63 & 3.00 & 174.64 & 30.94 & 0.91 \\
\hline SCH 2 & 7.27 & 6.67 & 2.60 & 126.08 & 24.88 & 0.81 \\
\hline SCH 3 & 9.06 & 7.96 & 3.05 & 219.96 & 36.87 & 0.96 \\
\hline SCH 4 & 8.60 & 7.46 & 2.96 & 189.90 & 33.85 & 0.90 \\
\hline SCH 5 & 8.60 & 7.46 & 2.79 & 179.00 & 33.61 & 0.86 \\
\hline SCH 6 & 7.94 & 7.10 & 3.00 & 169.12 & 29.13 & 0.93 \\
\hline SCH 7 & 7.30 & 6.18 & 2.63 & 118.65 & 23.97 & 0.80 \\
\hline SCH 8 & 8.63 & 7.18 & 2.96 & 183.41 & 32.76 & 0.96 \\
\hline
\end{tabular}

